\title{
STATISTICAL EVALUATIONS OF MORPHOLOGICAL AND ANATOMICAL CHARACTERISTICS OF DRACOCEPHALUM THYMIFLORUM (LAMIACEAE) POPULATIONS IN IRAN
}

\author{
M. Sheidai and F. Koohdar* \\ Faculty of Life Sciences \& Biotechnology, Shahid Beheshti University, Tehran, Iran \\ ${ }^{*}$ E-mail:f_koohdar@yahoo.com
}

(Received 11 June, 2017; Accepted 9 August, 2017)

\begin{abstract}
Dracocephalum (dragonhead) with about 60 to 70 species is mostly annual or perennial herbs or subshrubs. These species have medicinal values including anticancer, antioxidant, ant hypoxic and immune modulator activities. Dracocephalum thymiflorum grows in limited areas in Iran and forms few local populations and is extensively used by locals. We have no information on anatomical and morphological features of these medicinal species in the country. Clustering and PCA ordination of the studied populations based on morphological and anatomical data separated some of these populations from the others suggesting the existence 2 varieties within this species.
\end{abstract}

Key words: anatomy, Dracocephalum thymiflorum, Iran, morphology, variety

\section{INTRODUCTION}

Dracocephalum (dragonhead) is a genus with about 60 to 70 species in the family Lamiaceae, that grows in alpine and semidry regions mainly in temperate Asia, with a few species occurring in Europe, and one species in North America (Brach and Song 2006).

They are mostly annual or perennial herbs or sub shrubs, growing to 15-90 cm tall. Most of the species in the genus are of medicinal and chemical importance (Maham et al. 2013, Sonboli et al. 2011). These species have medicinal values including anticancer, antioxidant, antihypoxic and immune modulator activities (Zeng et al. 2010).

In total eight Dracocephalum L. species have been reported in Iran that grow in north and central parts of the country (Rechinger 1982). Dracocephalum thymiflorum L. grows in limited areas in Iran and forms few local populations and extensively used by locals and therefore are subject to be reduced in number or elimination from the natural habitat (Koohdar et al. 2015).

Koohdar et al. (2015) show although Dracocephalum thymiflorum populations are few in number and are confined to some ecological places, they showed good within-population genetic variability and limited amount of among population gene flow. 
The usefulness of the structure of stem and leaf for species identification in the family Lamiaceae has been demonstrated (Metcalfe and Chalk 1972, Kahraman et al. 2010).

We have no information available about anatomy and morphological diversity of these medicinal species in the country. Therefore, we collected Dracocephalum thymiflorum populations of some ecological places with the aim to identify them and produce basic taxonomic information on them. These results may lead to identify of the subspecies.

\section{MATERIALS AND METHODS}

\section{Plant materials}

Extensive field visits and collections were undertaken during 2014-2015. For morphological studies 15 plant specimens were randomly collected from 5 geographical populations and for anatomical study 3 geographical populations were randomly collected. Details of localities are provided in Table 1. Voucher specimens are deposited in the Herbarium of Shahid Beheshti University (HSBU).

\section{Morphological studies}

Altogether 19 morphological characters (1 qualitative, 18 quantitative) were studied (Table 2). ANOVA (analysis of variance) was performed to show morphological difference among the populations, while PCA (principal components analysis) biplot was used to identify the most variable morphological characters among the studied populations (Podani 2000). PAST version 2.17 (Hamer et al. 2012) was used for multivariate statistical analyses of data. Morphometrical characters were first standardised (mean $=0$, variance $=1$ ) and used to establish Euclidean distance among pairs of taxa. For grouping of the plant specimens, PCA (multidimensional scaling) with PAST program were used (Podani 2000).

\section{Table 1}

The studied Dracocephalum thymiflorum populations from Mazandran Province, their geographical features and voucher number

\begin{tabular}{llcccc}
\hline Locality & Altitude $(\mathrm{m})$ & Longitude & Latitude & Voucher number \\
\hline 1 & Namarestagh & 2370 & 520328.8 & 360328.8 & HSBU-2014370 \\
2 & Savadkuh & 2225 & 525550 & 355006 & HSBU-2014371 \\
3 & Kelardasht & 3100 & 511667 & 365167 & HSBU-2014372 \\
4 & Siah Bisheh & 2200 & 511818 & 361304 & HSBU-2014373 \\
5 & Ramsar & 21 & 503025 & 363430 & HSBU-2014374 \\
\hline
\end{tabular}




\section{Anatomical studies}

Embedded materials were prepared as follows: adult plant samples were excised and immediately fixed in formalin-acetic acid-alcohol (FAA) (formalin 5\%: acetic acid 5\% and 50\% ethanol 90\%) (Jensen 1962) for 48 to $72 \mathrm{~h}$, and stored at $4{ }^{\circ} \mathrm{C}$ until sectioning. Then dehydrated in a graded ethanol series and embedded in $70 \%$ ethanol. After preparation of free transverse hand sections of the lamina and stem samples were washed with distilled water and placed in 5\% sodium hypochlorite solution for $20 \mathrm{~min}$ for clearing and rinsed with distilled water. The sections were stained with methyl blue and carmine and mounted on the slides using Canada balsam. Thin cut sections were observed under a microscope fitted with digital camera. Details of morphological characters are provided in Table 3.

Table 2

Morphological characteristics in Dracocephalum thymiflorum populations

\begin{aligned} & \hline No. Morphological characters \\ & \hline 1 plant height \\ & 3 length of basal leaf \\ & 4 width of basal leaf \\ & 5 length of petiole in basal leaf \\ & 6 width of stem leaf \\ & 7 length of petiole in stem leaf \\ & 8 length of inflorescence leaf \\ & 9 width of inflorescence leaf \\ & 10 length of petiole in inflorescence \\ & leaf \\ & 11 number of veins in calyx \\ & 12 size of tooth in calyx \\ & 13 length of calyx \\ & 14 width of calyx \\ & 15 length of corolla \\ & 16 width of corolla \\ & 17 length of nutlet \\ & 18 width of nutlet \\ & 19 colour of calyx \\ & \hline\end{aligned}

Table 3

Anatomical characteristics in Dracocephalum thymiflorum populations

\begin{aligned} \hline No. & Anatomical characters \\ \hline 1 & length of epidermis in stem \\ 2 & length of collenchyma in stem \\ 4 & length of parenchyma in stem \\ 5 & length of sclerenchyma in stem \\ 6 & length of upper phloem in stem \\ 7 & length of lower phloem in stem \\ 8 & length of pith in stem \\ 9 & length of transects in stem \\ 10 & length of simple hair in stem \\ 11 & length of glandular hair in stem \\ 12 & number of layers of parenchyma \\ & in stem \\ 13 & number of layers of collenchyma \\ & in stem \\ 14 & number of layers of xylem in stem \\ 15 & length of upper epidermis in leaf \\ 16 & length of collenchyma in leaf \\ 17 & length of parenchyma in leaf \\ 18 & length of phloem in leaf \\ 19 & length of xylem in leaf \\ 20 & length of lower epidermis in leaf \\ \hline & \end{aligned}


Anatomical characters in 3 populations (Siah Bisheh, Ramsar and Namarestagh) were first standardised (mean $=0$, variance $=1$ ) and used to establish Euclidean distance among pairs of taxa. For grouping of the plant specimens, The UPGMA (unweighted paired group using average) as well as ordination methods PCA (principal components analysis) with PAST program were used (Podani 2000).

ANOVA (analysis of variance) was performed to show anatomical differences among the populations, while PCA (principal components analysis) biplot was used to identify the most variable morphological characters among the studied populations (Podani 2000). PAST version 2.17 (Hamer et al. 2012) was used for multivariate statistical analyses of data.

\section{RESULTS}

Morphometry

ANOVA test performed for quantitative morphological characters showed significant difference $(\mathrm{P}=0.01)$ among the studied populations.

PCA biplot analysis of morphological characters revealed that characters like length of basal leaf, length of inflorescence leaf, colour of calyx (green or purple), length of stem leaf, width of stem leaf, length of petiole in inflorescence leaf, length of calyx, number of veins in calyx are the most variable morphological characters and can be used in distinguished of the populations (no figure).

Different clustering and ordination methods produced similar results; therefore only PCA plot is presented (Fig. 1). PCA plot separated each population based on morphological characters studied. This result showed that the

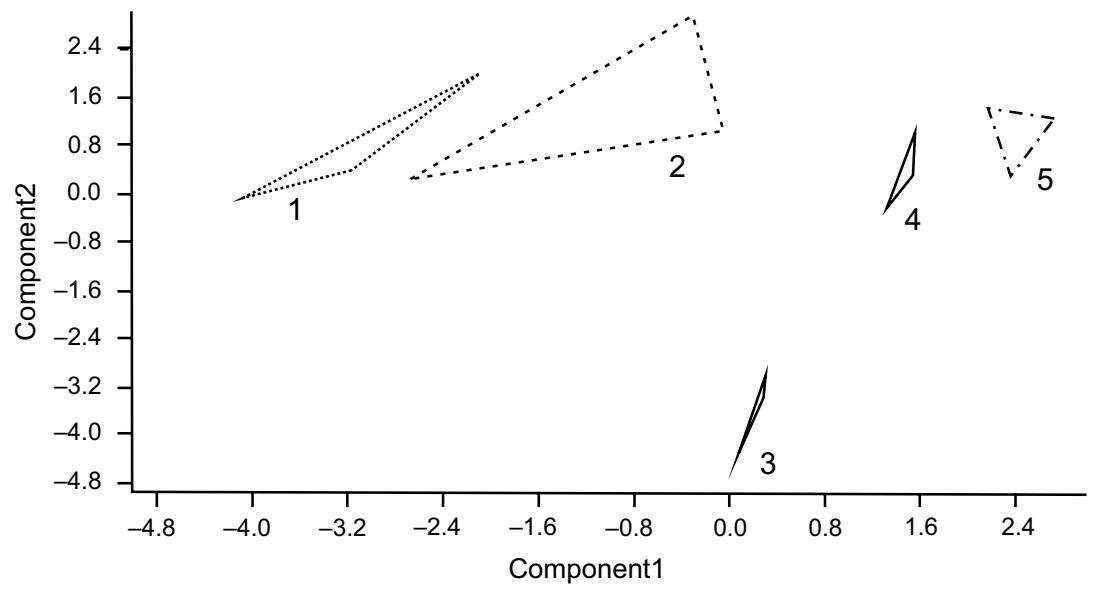

Fig. 1. PCA plot of Dracocephalum thymiflorum populations (populations 1-5 are according to Table 1) 
Table 4

Results of anatomical features in Dracocephalum thymiflorum populations

\begin{tabular}{lccc}
\hline Characteristics $(\mu \mathrm{m})$ & Siah Bisheh & Namarestagh & Ramsar \\
\hline 1) length of epidermis in stem & 30.9 & 38.86 & 24.41 \\
2) length of collenchyma in stem & 358.82 & 127.78 & 271.25 \\
3) length of parenchyma in stem & 122.8 & 62.66 & 104 \\
4) length of sclerenchyma in stem & 30.9 & 20.6 & 25.56 \\
5) length of upper phloem in stem & 47.92 & 29.83 & 38.44 \\
6) length of xylem in stem & 190.94 & 117.8 & 278.96 \\
7) length of lower phloem in stem & 52.14 & 49.9 & 64.21 \\
8) length of pith in stem & 1535.99 & 976.64 & 1260.63 \\
9) length of transects in stem & 2183.98 & 1398.62 & 1770.97 \\
10) length of simple hair in stem & 63.89 & 65.28 & 98.66 \\
11) length of glandular hair in stem & 19.9 & 30.77 & 38.57 \\
12) number of layers of parenchyma in stem & 10 & 12 & 16 \\
13) number of layers of collenchyma in stem & 5 & 4 & 4 \\
14) number of layers of xylem in stem & 24 & 13 & 14 \\
15) length of upper epidermis in leaf & 80.25 & 57.14 & 79.59 \\
16) length of collenchyma in leaf & 215.2 & 134.86 & 212.12 \\
17) length of parenchyma in leaf & 299.25 & 293.72 & 210.27 \\
18) length of phloem in leaf & 143.65 & 77.72 & 141.48 \\
19) length of xylem in leaf & 180.25 & 114.29 & 178.52 \\
20) length of lower epidermis in leaf & 57.25 & 47.12 & 54.21 \\
\hline
\end{tabular}

studied morphological characters like length of basal leaf, length of inflorescence leaf, colour of calyx distinguished the Ramsar, Siah Bisheh and Kelardasht populations from the Namarestagh and Savadkuh populations.

\section{Anatomy}

In anatomical study we selected 3 populations from the 5 populations in morphology study. Results of anatomy in stem and leaf in studied population are provided in Figure 2 and Table 4.

Different clustering and ordination methods produced similar results; therefore only UPGMA cluster is presented (Fig. 3). UPGMA cluster of Dracocephalum thymiflorum populations based on anatomical features like length of epidermis and shape of stem separated the Namarestagh population from the others. Therefore, anatomical characters can be used in Dracocephalum thymiflorum taxonomy. 

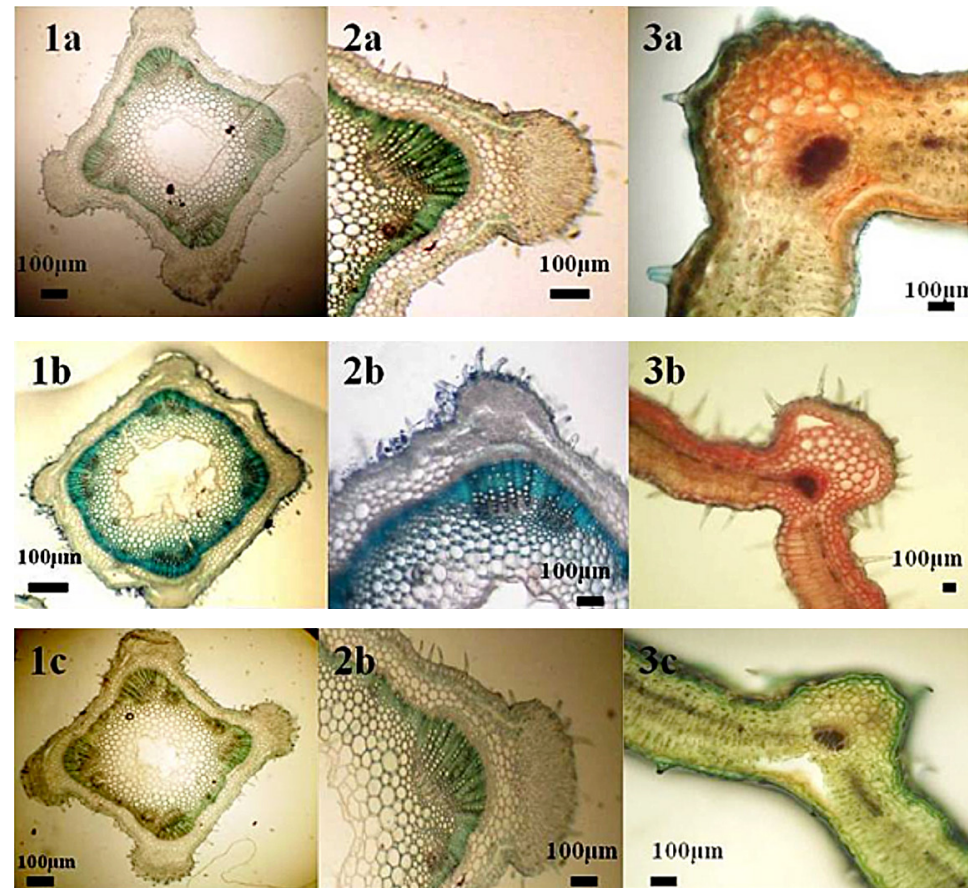

Fig. 2. Transverse sections of the stem and leaf: $1 \mathrm{a}, 2 \mathrm{a}$ and $3 \mathrm{a}=$ Siah Bisheh population; $1 \mathrm{~b}$, $2 \mathrm{~b}$ and $3 \mathrm{~b}=$ Namarestagh population, $1 \mathrm{c}, 2 \mathrm{c}$ and $3 \mathrm{c}=$ Ramsar population

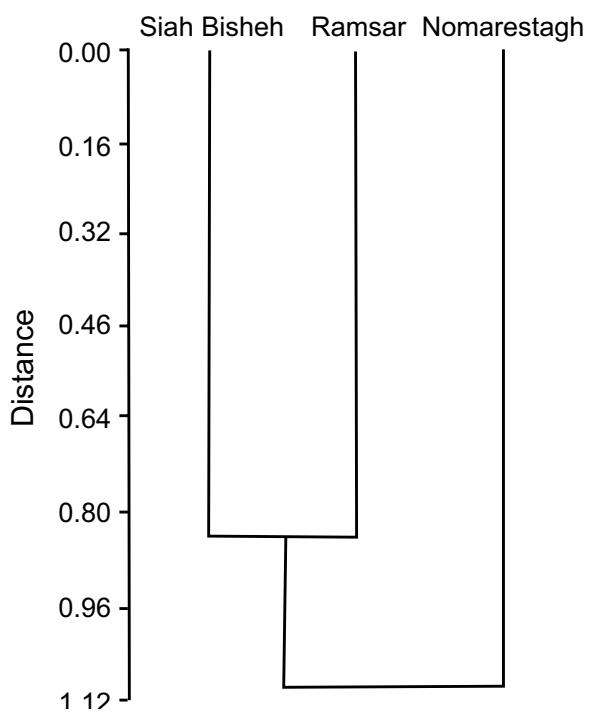

Fig. 3. UPGMA dendrogram of Dracocephalum thymiflorum populations 


\section{DISCUSSION}

Koohdar et al. (2015) pointed out that the studied populations are genetically different, based on ISSR marker on the same population. The populations Namarestagh and Savadkuh showed higher degree of genetic affinity and were placed close to each other. The populations Ramsar, Siah Bisheh and Kelardasht showed some degree of intermixture. among geographical populations of a single species, separation of populations on PCA plot and significant morphological differences also are adequate reasons to consider these populations as separate ecotypes. According to Knaus (2008), "if we take the species to be the unit of distinction, the infra-taxa (the subspecies, the variety and the ecotype) are consequently no distinct the process in which a group of organisms diverge from being one cohesive group to becoming two or more distinct groups is the process of speciation". Stebbins (1993) also included the idea that "species are systems of populations, which resemble each other, yet contain genetically different ecotypes that could be arranged in a continuous series. These allopatric infra-specific categories are usually recognized as infra-taxa".

Therefore, based on morphological and anatomical data, we separated some of these populations from the others suggesting the existence 2 varieties within this species. We will introduce these new varieties with its details in our next publication.

\section{REFERENCES}

Brach, A. R and Song, H. (2006): eFloras: New directions for online floras exemplified by the Flora of China Project. - Taxon 55: 188-192. https://doi.org/10.2307/25065540

Hamer, Ø., Harper, D. A. T. and Ryan, P. D. (2012): PAST: paleontological statistics software package for education and data analysis. - Palaeontol. Electron. 4: 9.

Jensen, W. A. (1962): Botanical histochemistry: Principles and practice. - W. H. Freeman, San Fransisco, 408 pp.

Kahraman, A., Celep, F. and Dogan, M. (2010): Anatomy, trichome morphology and palynology of Salvia chrysophylla Stapf (Lamiaceae). - S. Afr. J. Bot. 76: 187-195. https:// doi.org/10.1016/j.sajb.2009.10.003

Knaus, B. J. (2008): A fistful of Astragalus: phenotypic and genotypic basis of the most taxon rich species in the North American flora. - PhD Thesis, Oregon State University, USA, 143 pp.

Koohdar, F., Sheidai, M., Attar, F. and Talebi, S. M. (2015): Population genetic structure and genetic diversity in Dracocephalum thymiflorum L. (Lamiaceae) populations in Iran. - Mol. Plant Breed. 19: 1-7. https://doi.org/10.5376/mpb.2015.06.0019

Maham, M., Akbari, H. and Delazar, A. (2013): Chemical composition and antinociceptive effect of the essential oil of Dracocephalum moldavica L. - Pharmaceut. sci. 18: 187-192.

Metcalfe, C. R. and Chalk, L. (1972): Anatomy of the Dicotyledons. Vol. 2. - Oxford University Press, Oxford. 
Podani, J. (2000): Introduction to the exploration of multivariate data. - Backhuys Publishers, Leiden, Netherlands.

Rechinger, K. H. (1982): Dracocephalum. - In: Rechinger, K. H. (ed.): Flora Iranica, vol. 150. Akademische Druck, U. Verlagsanstalt, Graz, Austria, pp. 218-230.

Sonboli, A., Gholipour, A., Mirjalili, M. H. and Amini Rad, M. (2011): Molecular characterization of Iranian Dracocephalum (Lamiaceae) species based on RAPD data. - Acta Biol. Szeged. 55: 227-230.

Stebbins, G. L. (1993): Concepts of species and genera. - In: Editorial Committee (eds): Flora of North America, vol. 1(11). Oxford University Press, New York, pp. 229-246.

Zeng, Q., Jin, H. Z., Qin, J. J., Fu, J. J., Hu, H. J., Li, J. H., Yan, L., Chen, M. and Zhang, D. W. (2010): Chemical constituents of plants from the genus Dracocephalum. - Chem. Biodivers. 7: 1911-1929. 